\title{
Reform of Air Pollution Control Engineering Based on Mutual Promotion of Scientific Research, Teaching and Independent Innovation
}

\author{
Jingcai Chang ${ }^{1}$, Rui Wang ${ }^{1}$, Peng Wang ${ }^{2}$, Haixia Zhao ${ }^{1}$, Pu Wang ${ }^{1}$, Chunyuan $\mathrm{Ma}^{2}$, * \\ ${ }^{1}$ School of Environmental Science and Engineering, Shandong University, Qingdao, China \\ ${ }^{2}$ National Engineering Laboratory for Reducing Emissions from Coal Combustion, Engineering Research Center of \\ Environmental Thermal Technology of Ministry of Education, Shandong Key Laboratory of Energy Carbon Reduction and \\ Resource Utilization, School of Energy and Power Engineering, Shandong University, Jinan, China \\ *Corresponding author
}

\begin{abstract}
Air pollution engineering is a core course for environmental engineering, covering many contents such as emissions control policy, transformation processes, environmental hazards and control technologies. Aiming to the existing teaching problems of air pollution control engineering course including falling behind the development of Double Top-Class construction and other disciplines retardant teaching content, lagging hot contents of the study, and weak context awareness, an improved scheme was proposed, namely, reform of Air Pollution Control Engineering based on mutual promotion of scientific research, teaching and independent innovation. The research and practice were carried out from three aspects of teaching, learning and practice method. Thus formed the teaching reform concept of "mixed full-time and part-time teaching team, learning process with time and space virtual and real extension, and integration and sharing practice resource". The result from this way was fairly close to the goal of "knowledge inheritance and innovation, subject advantage accumulation, social demand embodiment, and senior talent training", improving the teaching quality of the course and achieving good teaching.
\end{abstract}

Keywords: Air Pollution Control Engineering, Scientific research, Teaching, Innovation

\section{“教研互促、重在创新”构建 “大气污染控制工程”教 学改革研究}

常景彩 ${ }^{1, *}$ ，王睿 ${ }^{1}$, 赵海霞 ${ }^{1},{\text { 王璞 }{ }^{1} \text {, 王鹏 }{ }^{2} \text { ，马春元 }}^{2}$

${ }^{1}$ 山东大学环境科学与工程学院, 青岛, 中国

${ }^{2}$ 山东大学能源与动力工程学院, 燃煤污染物减排国家工程实验室, 环境热工技术教育部工程研究中心, 山东省 能源碳减排技术与资源化利用重点实验室，济南，中国

“通讯作者

\section{中文摘要}

大气污染控制工程是高校环境工程的专业主干课程之一, 主要讲授大气污染防治与控制的原理与技术。 为推进精品课程建设, 加强授课效果, 针对该课程的特点, 结合多年来的教学实践和体会, 充分运用 现代化教学手段和行业从业优势, 实行启发式教学突出重点难点。将情景定制引入教学, 强化 “教研 互促、重在创新” 的教学理念, 通过构建多维教材体系、辅助教学方法以及教学考核体系, 做到理论 教学与能力培养并重, 为学生的学习和就业打下良好基础。

关键词：教学改革；大气污染控制工程；教研互促；创新 


\section{1. 引言}

环境科学与工程学科涵盖面广知识体系复杂, 《大 气污染控制工程》专业课既自成体系又与其他学科交叉 渗透, 内容架构复杂、抽象、问题多、知识联系性强, 原有的粗放浏览教学模式使得教学效果有限, 普遍存 在：内容繁多基础知识面宽教学学时短、关门授课跟不 上时代教材落后于学科进展、重知识轻能力重理论轻实 践 “教学用” 匹配性差等问题, 为此众多高校进行了系 列教改探索, 形成专属特色, 并取得良好教学效果 ${ }^{[1-5]}$ 。 如中南大学从优化课程理论教学体系、丰富课堂教学方 法与手段、创新实践教学培养环节以及拓展当前学科热 点与前沿内容等方面, 借助多媒体演示、互动式讨论和 案例教学相结合的方式, 突出应用技术和工程实践 ${ }^{[6]}$ 。 辽宁工业大学采用互动式、互换式和案例讨论式的课堂 教学方法, 把设计和创新思想引入课程教学, 用课内实 验、课程设计、分组报告和闭卷考试四部分对学生进行 全面考核和评价 ${ }^{[7]}$ 。山西大学的《大气污染控制工程课 程设计》改革, 使得全过程更加体系化、合理化并具有 火电行业特色 ${ }^{[8]}$ 。华北水利水电大学基于对布鲁姆 “掌 握学习” 先进教育理论有针对性地对课程进行了改革 [9]。浙江工业大学利用成果导向教育去反向设计教学过 程, 正向突出教学重点 ${ }^{[10]}$ 。上海理工大学利用多媒体信 息技术, 采用案例法、引导法、启发法、线上学习与线 下讨论相结合等多种教学方法, 保证教学内容生动新颖 前沿 ${ }^{[11]}$ 。清华大学提出了大气污染控制工程理论、大气 污染控制工程实验和大气污染控制工程设计 “三位一 体” 的课程体系 ${ }^{[12]}$, 进一步的完善了实验项目与内容的 设计与优化、实验设备研发、实验教学方法的改进 ${ }^{[13]}$ 。 青海大学以培养学生工程应用能力、工程理念为主线, 改革理论教学及实践教学, 取得了较好的教学效果 ${ }^{[14]}$ 。

随着我国复合型大气污染形势严峻, 打赢 “蓝天保 卫战” 上升到国家战略层面, 大气污染防治技术学科也 在不断发展和丰富。山东大学也对《大气污染控制工程 课程》教学提出了更高的要求, 要求结合我校能源环境 的专业特色, 以 “双一流” 学科建设为目标, 对本课程 的教学方式、课程体系等进行改革。基于此, 作者提出 “教研互促、重在创新” 新动态发展模式, 即从教学理 念、学习方法、实践体系三个方面展开研究和实践, 最 终形成了 “教学过程专兼职混合模式、学习过程时空虚 实延伸模式、实践过程资源整合共享模式” 为核心的教 学改革理念, 激发学生围绕大气污染控制的核心问题, 从发现、背景、拓展、解决、发展过程进行多方位多视 角自发主动互动学习, 使得 “教学用” 过程得以最大程 度的延伸, 切实提升了课程教学质量, 可为《大气污染 控制工程》课程发展提供参考。

\section{2. 《大气污染控制工程》课程设置存在问题}

《大气污染控制工程》包括课堂教学、实验教学两 部分。其中理论教学 (54 课时)、课程实验 (16 课时)。 通过与中南大学等其他高校课程横向比较发现, 课程设 置主要存在以下几个问题: (1)内容繁多、基础知识面宽, 教学学时短。例如教材中 “气象学大气扩散” 理论阐述 深入, 而学生化学、数学基础跨度时间长接受效果差, 对需要自己推公式、选参数等产生抵触情绪, 教授过程 中学生明显学习兴趣及热情不足。授课教材内容涉及到 流体力学、化工原理等多门专业基础学科知识, 复杂抽 象问题多、知识联系性强, 但因整体学时短, 内容繁多, 老师的思维限制在教学大纲限定框架之内, 将理论应用 于实践能力提升部分教授不足; (2)教材滞后于时代, 落 后于学科进展。自 “九五” 规划首次实施污染物总量控 制策略到现在的 “十三五” 的二十五年时间, 空气污染 防治目标已经从污染物总量控制发展到环境空气质量, 管理模式从属地管理转向区域管理及联防联控, 治理对 象从能源耗费企业的 “达标排放” 扩展到机动车、船 舶、无组织散源排放等污染, 减排措施从倚重末端减排 转为结构减排、源头减排以及能源清洁化发展。尤其在 2013年大气国十条发布以后，大气污染防治技术飞速提 升和发展, 新知识、新技术层出不穷, 但原教材中新技 术或者热点介绍受成稿时间限制相对量少而不足。这与 《山东大学教材建设与管理办法》 (〔2017) 34号) 要 求的 “形成与学校学科建设相适应、课程体系相配套、 前沿领域相协调的, 满足教学改革与发展要求、立足学 术前沿、门类齐全的教材体系” 尚存在一定的差距; (3) 重知识轻能力、重理论轻实践、教研用匹配性差。课程 以理论教学为主, 实验课时少且分为 $4 \sim 5$ 个简易常规科 普技术 (水吸收气体中的丙酮、室内甲醛含量测定及旋 风(布袋) 除尘性能演示)。学生受限于实习场所、专 业普适性、资源有限性等问题的制约, 对环境问题感知 不够深入。(4)环境科学问题模拟仿真能力建设十分薄 弱。环境污染本身是一个复杂的多介质系统内的传输和 变化问题, 污染物在多介质环境系统内迁移转化的定量 或定性描述, 有助于学生理解污染物在湖泊、河流、海 洋、土壤、地下水以及大气中迁移转化规律, 而与此对 应的数学模型、数值模拟方法和模拟软件业已发展到一 定规模。同时我校燃煤污染物减排国家工程实验室, 侧 重于污染过程的能源环境问题机制机理解析和终端的 污染控制与资源化技术集成与产业化，若将该实验室系 统性、前瞻性的研究成果用于促进能源环境学科的整体 发展, 在课程设置上, 将更新的环境研究成果或测试评 价方法上及时收录到课程中, 可在最大程度上实现教学 指导实践, 科研反哺教学。

\section{3. “教研互促、重在创新” 新动态发展模 式的由来与创建}

“大气污染控制” 按照汉语释义可解读为使大气 污染处于控制者的占有、管理或影响之下。随着时代的 
发展具有创新、传承和发展的特征。大气污染控制课程 教学要点主要从两方面展开, 一是从立法的角度来理解 限制或禁止污染物的扩散。要求学生了解哪些排放的污 染物应受限制, 控制到什么程度, 这些污染物物质对人 体健康、经济环境、生态美学等的危害, 了解这些污染 物质在大气中的相互作用、污染物在大气中的迁移转化 规律等。二是从技术的角度来防、治大气污染。即采用 某种技术或方法、手段把污染物排放量降到合理的排放 程度, 该过程是利用某种装置来实现的, 因此需要进行 工程分析, 进行污染防治设备的研究、设计、建造、安 装和运行。课本内容是基础, 也是知识传承创新与学科 优势积累过程形成的重要成果。但授课过程若仅围绕课 本展开, 因课时和教材内容所限, 导致学生的思维限制 在教师思维和书本知识框架之内, 不利于学生问题意 识、质疑精神、批判性思维和创新能力的成长。这也反 映在前期《大气污染控制工程》课程调研意见中。在环 境专业104份学生问卷中, 希望借助课堂进一步增强理 论实践结合教学的学生占比 $56.3 \%$, 具有热点问题讲述 评论需求的学生占比 $26.6 \%$, 希望强化课程互动的学生 占比 $12.5 \%$ 。因此本文课程教改目标为: 力图体现学科 建设成果, 承担学科优势和知识成果传承角色, 同时体 现专业建设发展, 兼顾学生个人需求和人才培养需求, 通过构建 “教学过程专兼职混合模式、学习过程时空虚 实延伸模式、实践过程资源整合共享模式” 新的教学理 念, 旨在形成 “知识传承创新、学科优势积累、社会需 求体现、高级人才培养” 多角色的 “教研互促、重在创 新” 新动态发展模式。

\section{1. “教学过程专兼职混合模式” 教学理念}

“双一流”建设是一个动态的积累过程, 其中本科 人才培养质量、专业建设特色、就业质量等是建设世界 一流大学的重要基础、支撑和承载。更新教育思想观念, 遵循教育教学规律的基础上坚持本科教育内涵发展是 大学教育的发展趋势。“教” 和 “学” 的承担者承载和 传承着一个高校的传统、精神和文化。对专业课程而言, 从 “教” 入手, 要实现通识教育与专业教育、理论教学 与实践教学、专业基础教学与能力技能训练之间的关系 平衡。基于此, “教学过程专兼职混合模式” 理念具有 无可比拟的优越性。

“教学过程专兼职混合模式” 授课团队创建思路: 在本科教学规定的原则框架下, 以兼顾 “基础性、系统 性、前沿性和实用性” 为原则, 以提升学生解决问题过 程中获得知识和成就感为目标, 侧重于借助知识传承创 新、学科优势积累, 成立复合人才授课团队。其关键在 于聘请同行业资深教师或工程技术专家参与辅助教学, 授课教师不限于本学院内。

“教学过程专兼职混合模式”授课团队教学能力 提升方法: (1)课程负责人从顶层设计角度, 分解部分学 时, 用于本课程中前沿性和实用性内容的分配。分配过 程中着重体现学生知识结构和课程体系之间的平衡, 尤 其注重平衡通识教育与专业教育、理论教学与实践教
学、专业基础教学与能力技能训练之间的关系; (2)教学 团队成员从大类上分为学术型或应用型教学, 处于不同 专业背景下的教学主体人员自发跟踪国内外在大气污 染控制工程、大气科学、化学工程等相关领域取得的新 进展，教学团队专业技能、整体知识、实践能力和基础 素质均衡, 形成具有 “力求知识体系完善、教学内容前 沿、教学手段多样、教学方法创新” 特色的教学理念; (3)结合团队教师所处的科研环境和工作学习条件, 分别 针对大气污染治理的关键污染物组分一烟尘、硫、氮、 VOCs、汽车尾气，挑选各自领域内的典型实际案例对其 控制技术的核心问题进行针对性讲解，并可将教师自身 的教学、科研、工程、实践资源 (例如已有的研究项目、 成果、已经形成的工艺流程和装备等）纳入分章节的教 学内容范畴, 实现不同专业领域角色教师的资深专业资 源转化为优质教学资源。

“教学过程专兼职混合模式” 教学特点: (1)师生互 督互促。作为授课教师坚持采用 “深入浅出、寓教于乐、 循循善诱、教学共鸣” 的授课理念、践行 “教书育人” 精神, 精讲精练, 注重引发学生的思考和心理的触动; 作为学生要树立远大的理想, 恪守学生职责, 在融洽课 堂实践过程中形成举一反三, 前后联系的学习思维, 收 获学习的乐趣与精髓; (2)坚持学用互促。借助课本基础 内容完成学生基本技能、理论水平培养, 辅以教师擅长 的专业拓展教育, 激发学生的实践和创新能力。由传统 授课构成 (基础内容和基本实验) 拓展为综合课程结构

（基础内容、基本实验、专业发展、前沿成果、定制实 验、实践教学) , 强化学生对理论知识的理解和掌握; (3)发展情景定制培养。我校环境专业本科生深造概率实 际已到 $50 \sim 70 \%$, 该课程设置在三年级上学期, 学生大多 已经确定保研排位或考研目标, 绝大多数均进驻不同课 题组参与早期科学研究。根据学生发展规划, 在课程设 置中增设了与学生参与课题紧密相关的专题讨论和科 研实践汇报，极大激发了学生的学习自主性和问题导向 学习能力。

\section{2. “学习过程时空虚实延伸模式” 学习 理念}

“学习过程时空虚实延伸模式” 拓展原则：基于高 等教育的 “通才和专才教育” 目标指导, 整个教学过程 的规划, 侧重于锻炼学生的问题意识、质疑精神、批判 性思维和创新能力, 体现社会和高级人才培养需求, 着 重于让学生在不断解决问题的过程中得到知识和成就 感。除了常规的课堂设置、通识实验课、定制实验课设 置之外, 可以引导学生充分利用当前丰富的各类学习资 源, 突破课堂所限使学习范围和广度得以自由延伸, 目 标是从课堂延伸到课外、从书本延伸到互联网 + , 从理 论延伸到实践, 从学校延伸到社会。

“学习过程时空虚实延伸模式”拓展途径: (1)课件 编排遵循大纲统筹安排。按照教材和学院课程设置需求 统一进行课件编排, 梳理教学重点确定各块占比: 固定 排放源类产生污染物控制 (煤燃烧、PM、SOx、NOx、VOCs) 
相关的原理、技术方法和设备教学占比约 $65 \%$, 大气自 身环境容量与消化相关 (大气污染气象学、大气扩散浓 度估算模式、厂址选择）教学占比约 $15 \%$, 移动以及生 活排放源污染物控制教学占比约 $10 \%$, 其他如净化系统 设计等占 $10 \%$ 。(2)引导专业热点问题进入教学课堂。笁 选环境工程研究的大气专业热点问题引导进课堂, 通过 现有典型污染物治理技术的主题讲解，了解PM2. 5、 VOCS、臭氧等技术发展的紧迫性与主要研究前沿构成, 锻炼学生敏锐捕捉热点问题的能力, 深刻理解热点知识 产生和发展的过程, 确实提升学科教育的针对性和实效 性。(3)充分利用网络资源弥补课堂教育的有限性。课程 教学限于资源有限性制约，学生无法对环境问题深入感 知。例如粉尘的物理性质章节相对单一枯燥, 但结合 8 - 12 天津滨海新区爆炸事故, 凸显无视粉尘物化性质 违规堆放储存的危害性; 从明火一爆炸一剧烈爆炸一大 火熄灭一明火熄灭一残余清理一防止生化泄露等过程, 引导学生回顾爆炸、消防、化工、环保专业处置方法; 从环保部门对事故区域三处入海排水口、气象局启动气 象保障一级应急响应、海域应急采样和现场监视监测数 据, 引导学生深刻理解这些污染物质在大气中的相互作 用和在大气中的迁移转化; 通过政府相关部门对受污染 地表水的有效处置, 事故中心区土壤和地下水的分类处 置与修复, 引导学生学习危害事件后续处理的重要性和 科学性等等。从书本延伸到互联网 + , 从实践联系理论 强化学生的问题意识, 情景介入方式可让学生思索问题 解决方法过程中得到知识和成就感。

\section{3. “实践过程资源整合共享模式” 实践理 念}

《大气污染控制工程》课程涉及各种污染物的控制 技术, 实践是培养学生动手能力和工程概念的非常重要 关键环节之一, 通过实践教学使学生直观地理解并利于 掌握大气污染控制技术的基本原理和各种理论, 最终使 之学以致用, 将所学知识应用于实践, 服务于社会需求 和高级人才培养目标。

“实践过程资源整合共享模式” 实践理念的总体 思路: (1)借助通识实践设置服务教学大纲主体内容, 引 导学生将课堂学习密切联系实际应用, 拓展基础知识 面, 突出广博。如可以某一发电厂为例, 了解其执行的 环境标准, 认识煤燃烧过程及其生成物的转化和危害, 通过厂内现有的除尘、脱硫、脱硝等为污染物治理设施 加深课堂除尘和气态污染物吸收部分的学习心得, 通过 在线CEMS监测了解主要气体参数的换算和计算等, 将工 业生产过程污染物排放政策管理、环境危害、控制技术、 后续迁移转化路径等课堂知识进行有序衔接加深理解; (2)借助情景定制实践设置服务于学生关注热点问题，统 筹校内大气污染控制成果资源, 让学生参与学习、实践 讨论, 突出精深。如对PM2. 5关注的学生, 教材的处理 技术以机械除尘器和电除尘器为主, 其宏观可视直观性 强。但对应超低排放政策下的颗粒物变成了什么? 为什 么危害如此巨大, 这就需要结合学校承接的细颗粒物研
究课题, 将细颗粒产生、监测甚至物化形貌等微观过程, 借助先进科研仪器和设备, 变成为宏观可见的过程和数 据, 呈现在学生面前, 让将科研成果服务实验教学。 “实践过程资源整合共享模式” 教学理念的优势: (1)专业资源反哺课堂教学。环境专业性工作主要为咨询 类和设计类两种, 其中咨询类包括环境影响评价、环境 工程咨询、环境监理、环境技术评估、产品生命周期评 价、清洁生产等等, 设计类包括各种环境工程项目的设 计、配套设备安装、施工、调试等。大量的专业人员在 长年累月的职业生涯中积累了丰富的经验。例如教学内 容中扩散模式的计算本属于教学难点类内容, 对数学要 求基础高。但对专业人员来讲，利用环境评价工作常用 的大气估算工具软件, 可以快速估算出点源、面源、体 源、火炬源等污染源在不同情况下的自动距离、离散距 离等数据; 还有类似的烟图高度计算、落地最大浓度计 算软件等专业分析软件, 这样要求学生在掌握基本扩散 原理之后, 借助辅助计算软件练习可以轻松掌握本类内 容, 大大激发了学生的学习兴趣也加深学以致用的成就 感。(2)科研成果反哺课堂教学。当前, 我国城市大气污 染类型已由煤烟型污染向煤烟、石油复合型污染转变, 增加了控制与治理的难度, 在实际科研工作中, 大气污 染控制技术的热点也在不断转换，应用技术日益更新。 受教材频繁更新难度所限, 无法及时反映一些新的大气 污染控制技术热点和进展。而处于学术或应用教学专业 背景下的教学人员出于职业敏感性, 会自发跟踪国内外 在大气污染控制工程、大气科学、化学工程等相关领域 取得的新进展，捕捉热点问题的同时实时调整完善或拓 展个人的研究内容和方向。这类研究通常立足前沿、接 轨国际、强化实践，一般会同步建设一批重大科技基础 设施, 涌现出一批具有前瞻性、引领性的原创成果。在 学生掌握书本基础知识的前提下, 向学生讲述或引导学 生加入有关学科动态前沿的知识中来, 不但可以开拓他 们的视野, 同时可以培养他们科学思维和探索奥秘的能 力, 激发学习的兴趣, 让教学课堂从 “灌输” 变为 “乐 学”。(3)考核体系反哺课堂教学。新的考核体系体现了 学生的基本知识掌握、综合能力运用, 实践能力培养, 平时成绩（20\%）包括课堂作业、考勤、课堂讨论及发 言等，成果成绩（20\%）包括学生利用课余时间搜集环 保热点或参与课题成果展示，期末成绩（40\%）采用综 述论文的方式, 标题内容选取兼顾行业发展动态, 着重 于课外知识的获取增加专业知识的广度, 促使学生深入 理解我国现阶段的典型污染问题，同时利用互联网等平 台, 追踪行业发展前沿和专业分析, 形成以自主探究和 创新为特点的课堂学习成果。通过 “找源头、查进展、 析原因、思对策” 来提升理论与实践相结合的综合能 力, 切实提升课堂教学实践应用相互促进的基础教育效 果。 


\section{4. 教研互促、重在创新” 新动态发展模式 教改效果评价与分析}

《大气污染控制工程》教学改革涉及诸多方面, 包 括教学理念、教学方法、教材体系、实践体系、学习考 核体系等等。课程教改立足于基础专业技术知识理论, 同时紧跟国家、行业、专业工程技术发展步伐, 力图在 教改过程中凸显 “知识传承创新、学科优势积累、社会 需求体现、高级人才培养” 目标, 显出良好的教学效果, 深受学生好评。在《山东大学课堂教学评价 (2017)》 以学生为中心的评价体系中, 主课程教学环节获得 96. 11分, 课程设计教学环节97. 99分的优异成绩, 其效 果主要来源于如下教改亮点:

(1)前沿热点调研源于学生个人诉求。学生通过主题 提议、讨论参与、网络探索、课题交流等多手段参与课 堂教学, 行成20个小主题插入课堂教学章节。通过主题 热点课题设置, 发现绝大部分同学对前沿研究的了解需 求并不限于直接参与的课题, 反而超过 $80 \%$ 的同学倾向 于课题外, 视野拓宽需求强烈。基于此, 汇合后的调研 意见紧密贴合了大气污染控制行业前沿研究进展, 成为 学生广泛关注的大气污染公众热点。前沿小主题的课堂 插入式设计, 让教学课堂从 “灌输” 变为 “乐学”, 极 大提高了学生学习兴趣和热情, 为未来专业方向和就业 选择印下了深刻印象。

(2)科研成果强化学生基础认知。《大气污染控制工 程》课程近70\%内容为固定排放源类产生污染物控制。 随着国家对环境问题的高度重视, 绝大部分大气污染物 组分已被成熟的工艺或装备控制排放。但学生接触的相 对少且了解不深。例如在燃煤电站PM2.5超低排放治理 实施过程中, 大量的PM2. 5 控制装备已投入使用。教学 团队有来自燃煤污染物减排国家工程实验室专业做 PM2.5控制的老师，已将多年的科研成果转化为规模化 应用, 已经形成了集宣传、评价和展示为一体的实物模 型和视频集锦。借助校内资源资助与共享, 以视频和实 物模型对照的形式向学生介绍了脱硫、脱硝、除尘、 PM2. 5控制技术在工程上的实际应用实例, 深刻和清晰 表达了书本上的主流污染物控制技术和工艺, 学生学习 的目标性、积极性、主动性显著提升, 较采用灌输式教 学的课堂效果和教学质量提效显著。

(3)考核体系拓展学生综合能力。对于大三学生来 讲, 课程考试只是加强知识记忆, 而自己尝试小综述因 难度较大印象会更深刻, 因此期末考核环节变为综述论 文新方式。学生在课程学习过程同步接触研究课题, 新 知识繁多错乱, 有序梳理能力需要锻炼提升。期末按照 “找源头、查进展、析原因、思对策、作结论” 完整的 梳理链, 借助布置小综述论文形式提升学生理论与实践 相结合的综合能力。例如布置的《烧结烟气大气污染物 控制》综述, 既可以拓展知识面, 认识书本上无法体现 的某一具体行业, 同时在整理、撰写和总结研究进展的 过程中, 深刻感知和处理具体的环境问题。新考核体系 优势从细节上可以集中体现, 例如学生可从烧结过程排 放的烟尘、氮氧化物、硫氧化物等污染物回顾煤燃烧造
成的大气污染，了解国家环境标准与地方标准约束行业 排放现状，综述当前烧结污染物现实控制技术与课本上 基本控制技术之间的差距，分析当前控制技术与国内外 先进控制技术之间存在的不足，优选具有发展前景的控 制技术进行分析和可行性评价，表述个人见解并形成结 论。整个过程引导学生学习新知识、思考新问题并以情 景介入方式去思索问题解决方法，得到知识并获得成就 感。这样极大的锻炼了学生的综合能力, 开拓专业视野, 学会如何学习和借鉴已有的科研成果真正参与到环境 问题中来, 变被动学习为主动学习, 掌握的知识与技能 更加牢固。这种多元化评价体系更加客观, 有利于学生 学习效果的稳步提升。

\section{5. 结束语}

“教研互促、重在创新”新动态发展模 式促进《大气污染控制工程》教改的目的在 于完成知识传承创新、积累学科优势、体现 社会需求、培养高级人才。教学理念、教学 方法、教材体系、实践体系、考核体系的多 元化发展力图体现学科建设成果、承担学科 优势、传承知识成果，同时体现专业建设发 展, 兼顾学生个人需求和人才培养需求。激 发学生围绕大气污染控制的核心问题，多方 位多视角自发主动互动学习，使得 “教学 用” 过程得以最大程度的延伸, 实现素质教 育。力争借助新的教、学、用课程改革理念, 切实提升课程教学质量创建精品课程。

\section{致谢}

本文为山东大学教育教学改革研究专项经费《“教 研互促、重在创新”构建 “大气污染控制工程” 教学 改革研究》（项目编号：2019Y208）、国家自然科学基 金项目（面上） “脱硫废水荷电蒸发协同降温吸湿促进 细颗粒团聚过程及机制研究”（项目编号：51976109） 和国家重点研发计划 “燃煤电厂新型高效除尘技术及 工程示范”（项目编号：2017YFB0602902）项目的阶 段性成果之一。

\section{REFERENCES}

[1] Geng Chunxiang, An Hui, Zhang Qingdong and Wang Zhiwei, Teaching reform and exploration of Air Pollution Control Engineering $[\mathrm{J}]$, Education Teaching Forum.2010,33:175-176. 
[2] Lu Huixiong, Huang Rong and Cai Quanying, Reform and optimization of classroom teaching in Air Pollution Control Engineering[J], China Electric Power Education.2010,30:104-105.

[3] Miao Juan, Wei Xuefeng, Dong Tieyou, Li Mei Tang Hongyan and Ma Jianhua, Exploration of "Air Pollution Control Engineering" four in one teaching mode based on employment orientation[J], Read and Write Periodical.2010,7(9):57-58.

[4] Niu Xianchun, Zhou Jianmin and Zhong Huawen, Teaching reform of petrochemical characteristic for Air Pollution Control Engineering educational[J]. Guangdong Chemical Industry. 2010,37(05):273-274.

[5] Jiang Boqiong $\mathrm{Wu}$ Zuliang and $\mathrm{Lu} \mathrm{Hao,} \mathrm{The}$ importance of innovative comprehensive practice teaching of "Air Pollution Control Project"[J]. The Science Education Article Collects.2010,2:96-97.

[6] Xiao Xiyuan, On reflection and practical innovation in teaching the course of Air Pollution Control Engineering $[\mathrm{J}]$, Journal of Southwest China Normal University (Natural Science Edition). 2014,39(2):1 63-166.

[7] Shan Fengjun, Yu Changwu and Zhou Lidai. Teaching reform of Air Pollution Control Engineering[J]. Journal of Liaoning University of Technology (Social Science Edition),2018,20(2): 130-132.

[8] Gao Yangyan, Hao Yanhong and Meng Tao, Discussion on the reform of the course design of Air Pollution Control Engineering [J], Journal of Higher Education.2015,18:141-142.

[9] Feng Xiao, Yang Xiaoli and Li Haihua,Discussion on Classroom Teaching Reform of Air Pollution Control Engineering $\quad[\mathrm{J}, \quad$ Education Teaching Forum.2018,37:106-107.

[10] CHENG Zhuowei, YU Jianming, WANG Jiade and CHEN Jianmeng, An analysis of outcome-based education idea and implementation strategy-a case study of the course of Air Pollutant Controlling Engineering [J]. Journal of Zhejiang University of Technology (Social Science).2015,14(3):288-292.

[11] HUANG Yuandong, ZHANG Xiaodong and WANG Guan, Course system construction and teaching reform of Air Pollution Control Engineering [J]. Education Teaching Forum.2018,5:86-88.
[12] Wang Shuxiao, Course system construction and resource sharing of Air Pollution Control Engineering[J], China University Teaching.2018,6:19-24.

[13] Duan Fengkui, Hao Jiming, Wang Shuxiao, Duan Lei, He Kebin and Ma Yongliang, Construction of Air Pollution Control Engineering experimental course [J]. Experimental Technology and Management.2015,32(9):6-8.

[14] Yan Gang, Wang Tian and Huang Silei, Teaching practice of Air Pollution Control Engineering under the mode of engineering application training $[\mathrm{J}]$. Chemical Industry Times.2017,31(5):48-50. 